\title{
DEMANDA BIOQUÍMICA E QUÍMICA DE OXIGÊNIO NO RIO URAIM E O PROCESSO DE URBANIZAÇÃO NO MUNICÍPIO DE PARAGOMINAS-PA
}

Nathália Melo Giuliatti - nathaliagiuliatti@ hotmail.com Universidade do Estado do Pará - UEPA

Ana Beatriz Matos Rodrigues - anabrodriguesz@gmail.com Universidade do Estado do Pará - UEPA

Vinycius Lima Brito - vinyciuslima00@ gmail.com

Universidade do Estado do Pará - UEPA

Iran Abib Valente da Silva - profuepa@ yahoo.com.br

Universidade do Estado do Pará - UEPA

Antônio Pereira Junior - antonio.junior@uepa.br

Universidade do Estado do Pará - UEPA 


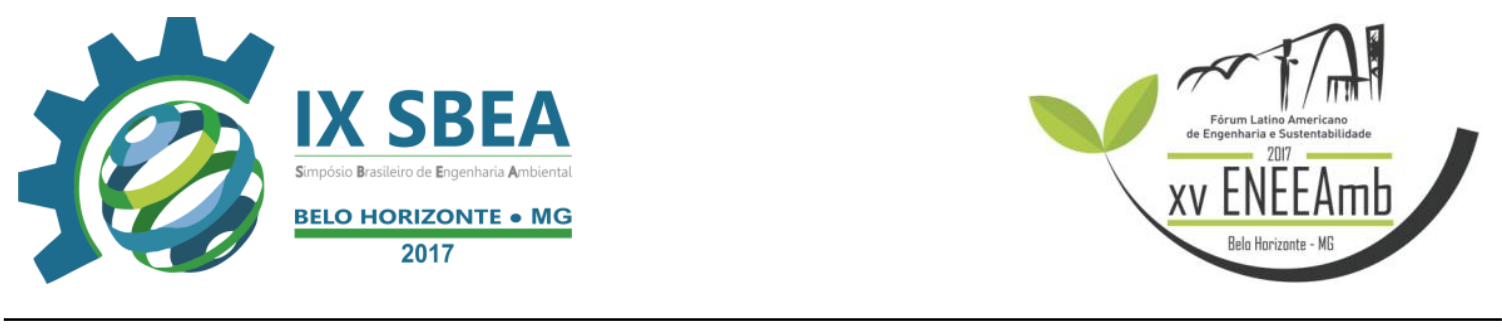

\section{RESUMO}

A preservação e o reaproveitamento de recursos hídricos exigem a adequação dos parâmetros físico-químicos e biológicos da água à legislação ambiental vigente. Nesse sentido, esta pesquisa teve como objetivo analisar quantitativamente a demanda bioquímica de oxigênio - DBO e a demanda química de oxigênio - DQO, em 4.250 metros, a partir do ponto de captação de água na Estação de Tratamento de Água (área de menor urbanização) até o lado esquerdo da ponte da PA 125 (área de maior urbanização), Paragominas-PA, bem como relacionar a variação desses parâmetros ao número de habitantes entre esses dois locais. A metodologia empregada foi observativa, sistemática, direta e foram observados os protocolos de análise estabelecidos pelas NBRs 10739:1989 e 12614:1992. Os dados obtidos foram tratados com uso do software BioEstat 5.3 (AYRES et al., 2007), com base na estatística descritiva (média, desvio padrão e coeficiente de variação) e uso da correlação linear de Pearson. A análise dos dados obtidos indicou que tanto a DBO quanto a DQO mantêm-se nos limites máximos permitidos, de acordo com a Resolução n.357:2005, do Conselho Nacional de Meio Ambiente CONAMA, e Chapman \& Kimstach (1996), respectivamente. Constatou-se ainda que, quanto mais urbanizada a área que margeia o rio Uraim, maior a DBO e a DQO, o que é prejudicial aos ecossistemas aquáticos, isso em face da ausência de saneamento básico adequado no município.

Palavras-chave: Rio, Parâmetros físico-químicos, Habitantes, Correlação de Pearson.

\section{INTRODUÇÃO E OBJETIVO}

A preservação e o reaproveitamento de recursos naturais, em especial os hídricos, são temas recorrentes na atualidade. Nesse contexto, faz-se necessária a gestão adequada desses recursos a fim de que a legislação ambiental seja obedecida e não ocorra danos ao ambiente hídrico. Apesar disso, há despejos, em corpos d'água, de resíduos e/ou efluentes oriundos de atividade urbana. Ademais, o elevado índice de urbanização causa o aumento da área impermeável da cidade, o que intensifica a lixiviação de matéria orgânica em direção ao curso d'água (SHARMA \& KANSAL, 2010).

Quando ocorre o despejo de matéria orgânica em excesso, há o aumento da população de micro-organismos que dela se alimenta e, portanto, do oxigênio por ela 
consumido para realização de atividades metabólicas. Essas atividades são de natureza biológica ou bioquímica. Por isso, o consumo daquele elemento é denominado demanda bioquímica de oxigênio (DBO). Esse conceito é essencial para análise da poluição, pois permite avaliar a "força poluidora" de um resíduo (BRANCO, 2010).

Além da DBO, a demanda química de oxigênio (DQO) também determina a quantidade de oxigênio necessária para degradação da matéria orgânica. No entanto, ela é feita por meio da oxidação química, capaz de oxidar tanto a matéria orgânica biodegradável quanto a não biodegradável (LAZZEREIS, 2013). A DBO e a DQO são quantificadas a partir do oxigênio consumido na decomposição da matéria orgânica.

Nessa perspectiva, esta pesquisa teve como objetivo quantificar a DBO e a DQO em 4.250 metros do curso do rio Uraim, no sentido montante - jusante, em área urbanizada do município de Paragominas-PA, bem como relacionar a variação desses parâmetros ao grau de urbanização da área de ambas as margens do rio.

\section{MATERIAL E MÉTODOS}

\subsection{FISIOGRAFIA DO MUNICÍPIO}

A pesquisa foi realizada no município de Paragominas, sudeste do estado do Pará, com população estimada em 108.547 habitantes (IBGE, 2016). O clima local é do tipo quente e úmido, com temperatura anual média de $26{ }^{\circ} \mathrm{C}$ e umidade relativa do ar de 81\% (BASTOS et al., 2010). A hidrografia é constituída pelas bacias hidrográficas do rio Gurupi e do rio Capim, mas apenas os rios Uraim e Paragominas, constituintes da microbacia do rio Uraim, atravessam o perímetro urbano (PINTO et al., 2009).

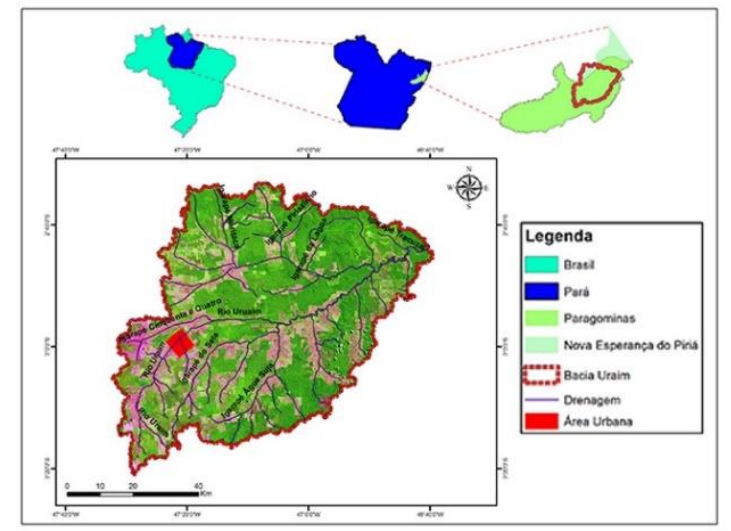

Figura 1 - Microbacia do rio Uraim Fonte: SANEPAR (2014) 


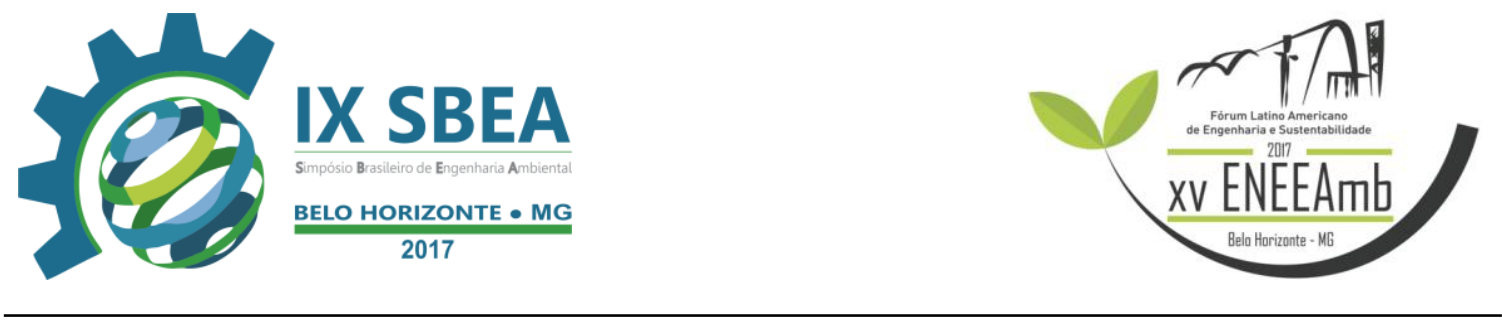

\section{2. ÁREA DE ESTUDO}

O rio Uraim, que possui vazão média anual de 268.423,35 m³/h, é essencial para os serviços de saneamento da cidade, pois abriga o ponto de captação de água para abastecimento público (SANEPAR, 2014). Da extensão total de 202 km, foram estudados 4.250 metros, com início no ponto de captação de água da Estação de Tratamento de Água - ETA de Paragominas-PA (área de menor urbanização) e fim próximo à ponte da PA 125 (área de maior urbanização), limite do bairro Industrial (Figura 2). O estudo foi realizado no mês de abril, período chuvoso da região.

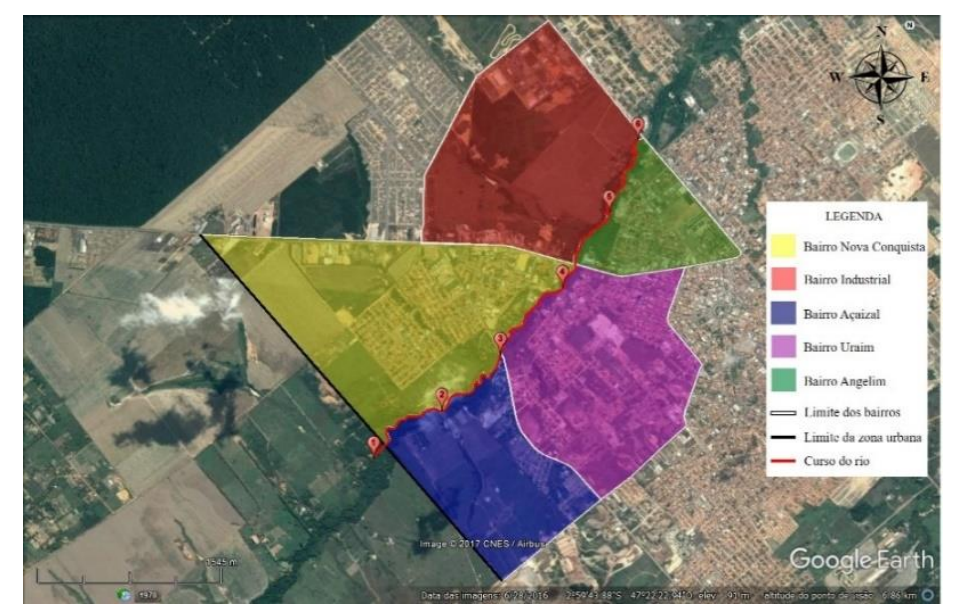

Figura 2 - Delimitação dos bairros que margeiam o rio Fonte: Autores (2017)

\subsection{CARACTERIZAÇÃO DA PESQUISA}

A metodologia de pesquisa empregada foi observativa, sistemática, direta, associada a levantamento de dados documentais com recorte temporal compreendido entre 2007 e 2017.

\subsection{COLETA DE DADOS}

Os seis pontos de coleta das amostras da água foram selecionados sob a condição de localizarem-se em áreas com menor (Ponto 1) e maior urbanização (Ponto 6): no local de captação de água da ETA de Paragominas e no lado esquerdo da ponte da PA 125, respectivamente. Dentre eles, localizaram-se os pontos P2, P3, P4 e P5 e, todos eles, distanciaram-se entre si em 850 m (Figura 3). 

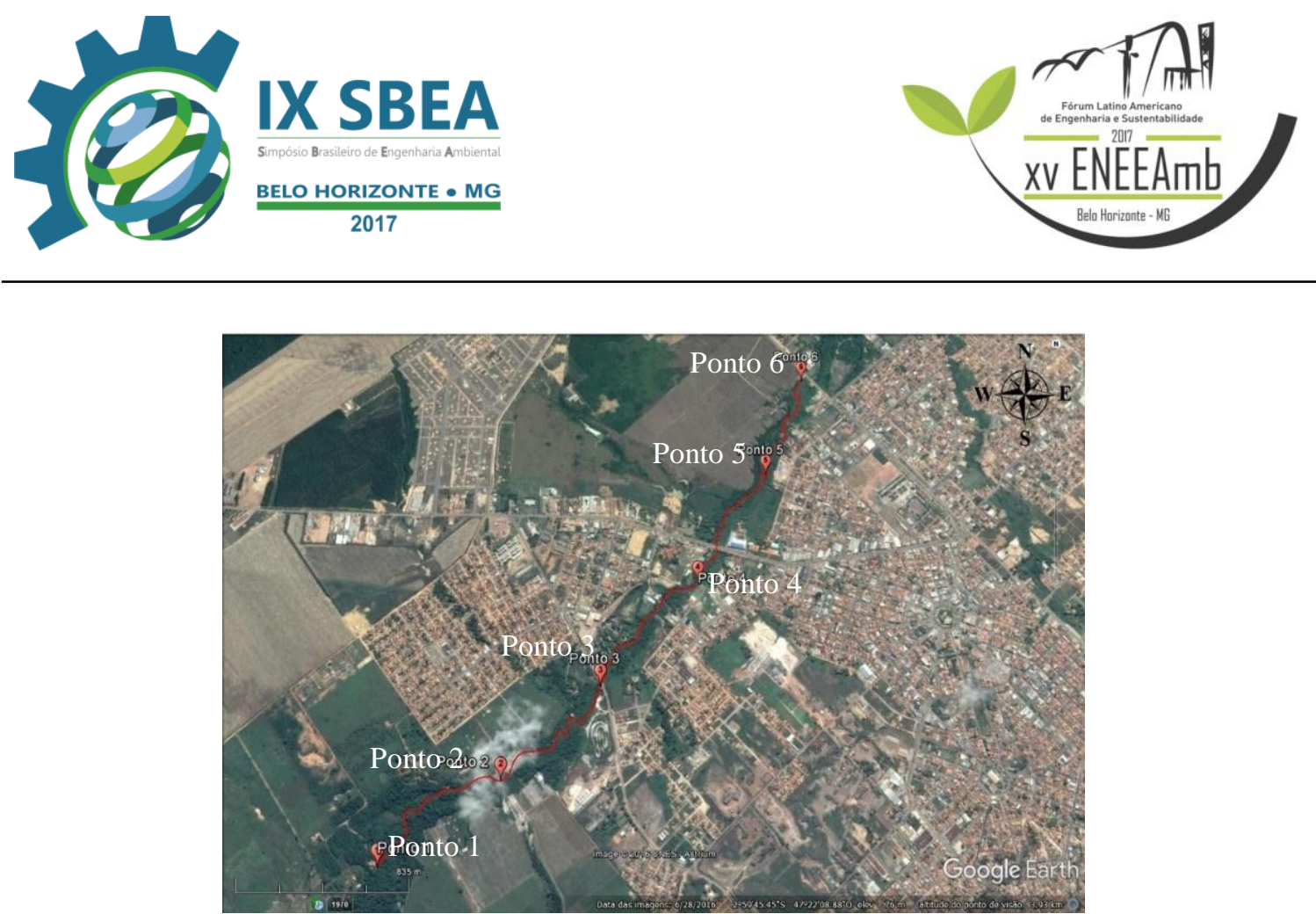

Figura 3 - Localização dos seis pontos de coleta. Paragominas - PA. Fonte: Google Earth (2016)

Para melhor localização dos seis pontos, foram identificadas as coordenadas geográficas, com o uso do Global Positioning System - GPS (Tabela 1).

Tabela 1 - Coordenadas geográficas dos seis pontos de coleta. Paragominas - PA.

\begin{tabular}{|c|c|c|}
\hline Ponto & Latitude & Longitude \\
\hline 1 & S 300'24.68" & $\mathrm{O} 47^{\circ} 22^{\prime} 52.83^{\prime \prime}$ \\
\hline 2 & S 300'11.62" & $\mathrm{O} 47^{\circ} 22^{\prime} 34.17^{\prime \prime}$ \\
\hline 3 & S 2059'56.31" & $\mathrm{O} 47^{\circ} 22^{\prime} 18.15^{\prime \prime}$ \\
\hline 4 & S 2'59'38.05" & $\mathrm{O} 47^{\circ} 22^{\prime} 01.12^{\prime \prime}$ \\
\hline 5 & S 2'59'17.36" & $\mathrm{O} 47^{\circ} 21^{\prime} 48.05^{\prime \prime}$ \\
\hline 6 & S 2 $2^{\circ} 58^{\prime} 57.34^{\prime \prime}$ & $\mathrm{O} 47^{\circ} 21^{\prime} 40.16^{\prime \prime}$ \\
\hline
\end{tabular}

Fonte: Autores (2017)

\subsection{AMOSTRAGEM DA ÁGUA E ANÁLISES QUÍMICAS}

O volume de água superficial coletado em cada ponto foi de 2 litros, em frascos de polietileno, com tampa, previamente esterilizados. As amostragens foram efetuadas em três dias consecutivos, sempre no mesmo horário (09h00min), com uma amostragem por dia em cada ponto, totalizando 18 amostras coletadas. Após as amostragens, elas foram encaminhadas para o Laboratório de Análises de Água da Agência de Saneamento de Paragominas-PA, onde foram analisados os parâmetros físico-químicos $\mathrm{DBO}$, com o uso de aerador e incubadora termostatizada, e DQO, com o emprego de banho maria, agitador magnético e termômetro químico. Os protocolos de análise utilizados foram os estabelecidos pela NBR 10739:1989, de determinação de oxigênio consumido em água, 


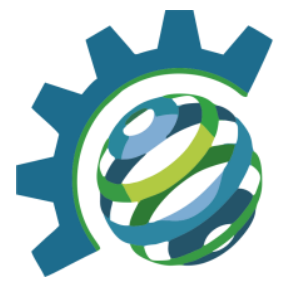

e pela NBR 12614:1992, que normatiza a análise de DBO realizada pelo processo de incubação de amostras inoculadas durante 5 dias a $20^{\circ} \mathrm{C}$.

\subsection{TRATAMENTO ESTATÍSTICO DOS DADOS}

Os dados laboratoriais obtidos foram tratados estatisticamente com o uso do software BioEstat 5.3 (AYRES et al., 2007), no qual empregou-se a estatística descritiva (média: utilizada para análise geral da qualidade da água do rio no que tange aos parâmetros analisados em relação aos limites estabelecidos para essa pesquisa; desvio padrão: para homogeneidade dos valores de DBO e DQO, nos pontos analisados; e coeficiente de variação: para expressar esse desvio em forma percentual e confirmar uma baixa dispersão). O coeficiente de correlação de Pearson $(r)$ indicou a correlação entre duas variáveis, de modo que quanto mais próximo de 1 o valor de $r$ for, maior a relação direta e quanto mais próximo de -1 , maior a relação inversa (BITTENCOURT, 2014).

\subsection{CORRELAÇÃO ENTRE OS DADOS OBTIDOS}

Para correlacionar os dados obtidos a partir das análises laboratoriais de DBO e DQO à urbanização, foram delimitadas cinco áreas que influenciam os seis pontos de coleta das amostras, observados o curso do rio que possui sentido de $\mathrm{P}_{1}$ a $\mathrm{P}_{6}$ e os limites territoriais dos 5 bairros que margeiam a extensão estudada (Figura 4).

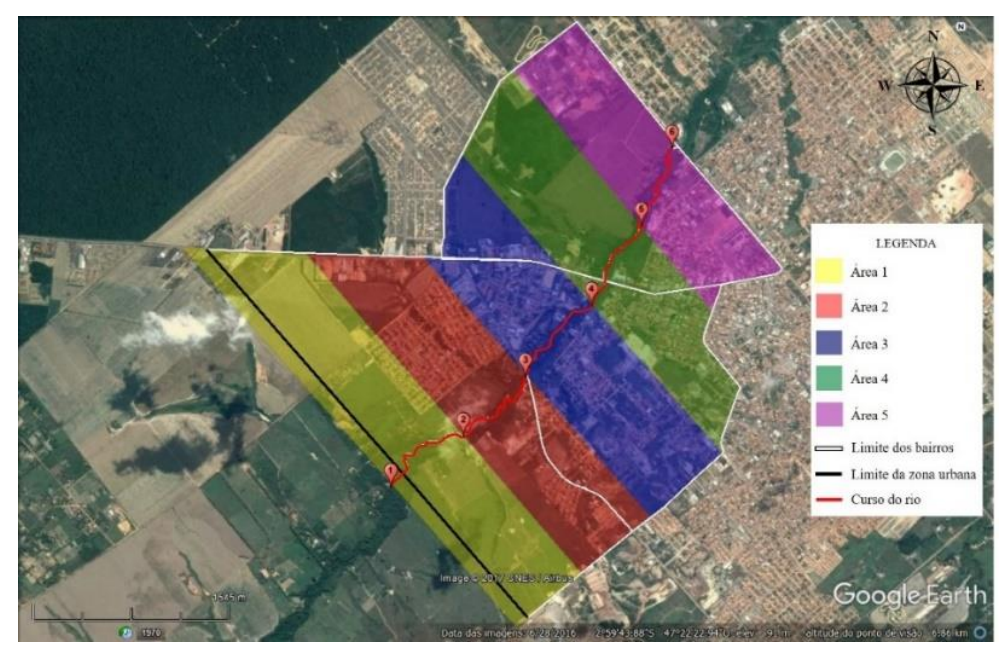

Figura 4 - Delimitação das áreas de influência nos pontos seis pontos de coleta. Paragominas - PA. Fonte: Autores (2017) 


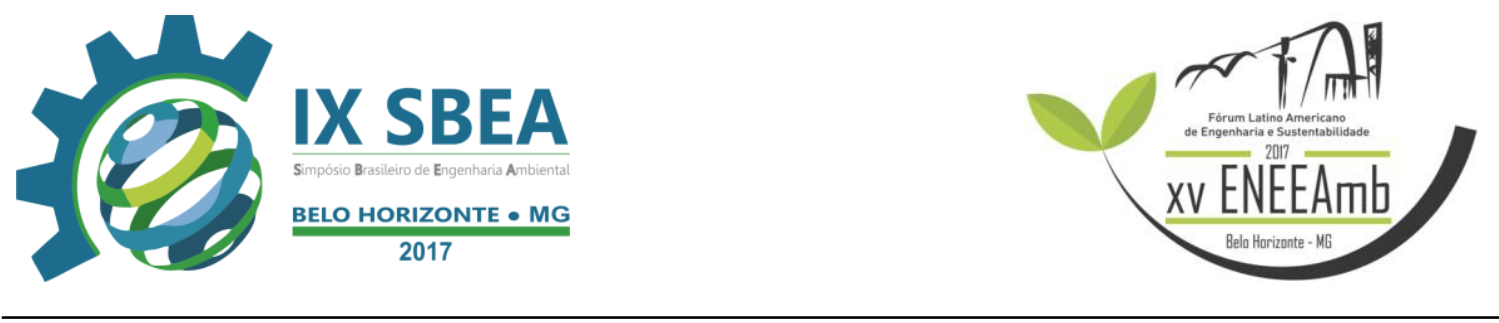

A população de cada área foi estimada com auxílio do mapa interativo, disponibilizado pelo IBGE, que permite que o usuário delimite uma área qualquer na tela e obtenha a quantidade aproximada de população total nela residente, com uso de dados provenientes do Censo Demográfico de 2010 (IBGE, 2010).

\section{RESULTADOS E DISCUSSÃO}

\subsection{QUANTO AOS VALORES PARA DBO e DQO E AOS PARÂMETROS} ESTABELECIDOS NOS PROTOCOLOS BASE

A análise dos dados obtidos para DBO e BQO indicou que ambos os valores estão dentro dos limites máximos permitidos (Tabela 2).

\begin{tabular}{|c|c|c|c|c|}
\hline \multirow{2}{*}{ Pontos } & DBO & DQO & \multicolumn{2}{|c|}{ Variações } \\
\hline & \multicolumn{2}{|c|}{ 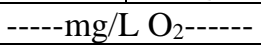 } & DBO & DQO \\
\hline $\mathrm{P}_{1}$ & 0,6056 & 1,06 & ------ & ------ \\
\hline $\mathrm{P}_{2}$ & 0,6653 & 1,17 & 0,0597 & 0,11 \\
\hline $\mathrm{P}_{3}$ & 0,8906 & 1,57 & 0,2253 & 0,4 \\
\hline $\mathrm{P}_{4}$ & 0,9976 & 1,76 & 0,107 & 0,19 \\
\hline $\mathrm{P}_{5}$ & 1,0906 & 1,92 & 0,093 & 0,16 \\
\hline $\mathrm{P}_{6}$ & 1,1010 & 1,94 & 0,0104 & 0,02 \\
\hline
\end{tabular}

Tal análise indicou que os valores encontrados, nos seis pontos analisados, para a primeira variável analisada (DBO), estão em conformidade com a Resolução n. 357:2005 - CONAMA, que estabelece valor máximo igual a $3 \mathrm{mg} / \mathrm{L} \mathrm{O}_{2}$ em águas doces de Classe 2. Para a segunda variável (DQO), essa análise indicou que tais valores obedecem ao preconizado por Chapman \& Kimstach (1996). Ambos afirmam que as concentrações de DQO observadas em águas superficiais não poluídas é de $20 \mathrm{mg} / \mathrm{L} \mathrm{O} 2$ ou menos. Portanto, a qualidade da água, em comparação com os valores bases, mostrouse adequada.

Em relação ao processo comparativo entre DBO e DQO, os dados obtidos, quanto aos valores médios para os seis pontos de coleta, indicaram que a média de DQO foi superior à de DBO (Tabela 3). 


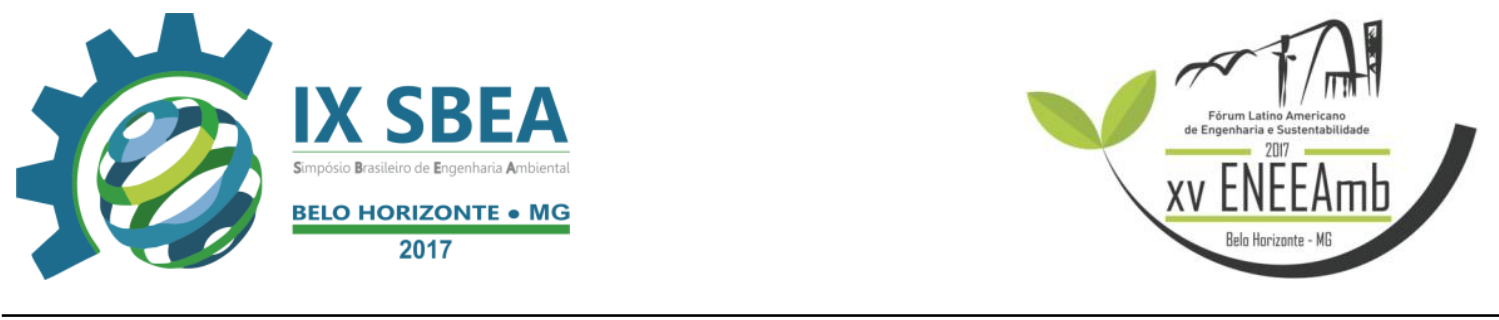

Tabela 3 - Média, Desvio Padrão (DP) e Coeficiente de Variação (CV), para a Demando Bioquímica do Oxigênio (DBO) e Demanda Química do Oxigênio (DQO) dos seis pontos analisados. Rio Uraim. Paragominas - PA.

\begin{tabular}{|c|c|c|c|c|}
\hline Variável ambiental analisada & Média & \pm & DP & $\mathrm{CV}(\%)$ \\
\hline $\mathrm{DBO}\left(\mathrm{mg} / \mathrm{L} \mathrm{O}_{2}\right)$ & 0,8913 & \pm & 0,2134 & 23,93 \\
\hline $\mathrm{DQO}\left(\mathrm{mg} / \mathrm{L} \mathrm{O}_{2}\right)$ & 1,57 & \pm & 0,3783 & 24,10 \\
\hline
\end{tabular}

Fonte: Autores (2017)

Os dados obtidos para DBO e DQO em cada ponto de coleta e a relação com a urbanização dos cinco bairros (Figura 5) indicaram que essas variáveis estão fortemente relacionadas (DBO, $r=0,9827$; DQO, $r=0,9824$ ), pois as demandas por oxigênio sofreram variações em decorrência da urbanização dos bairros que margeiam o rio (Figura 5). Dessa forma, o número de habitantes das áreas que influenciam cada ponto analisado influi nas concentrações de DBO e DQO.

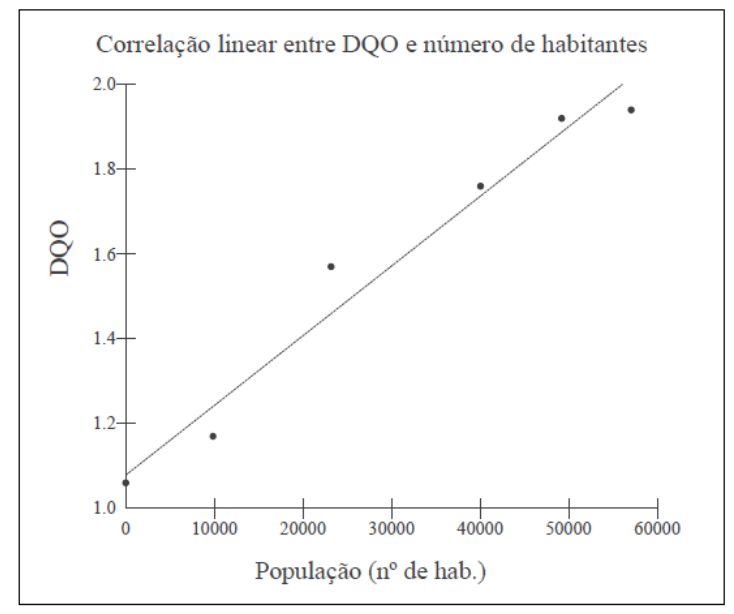

(a)

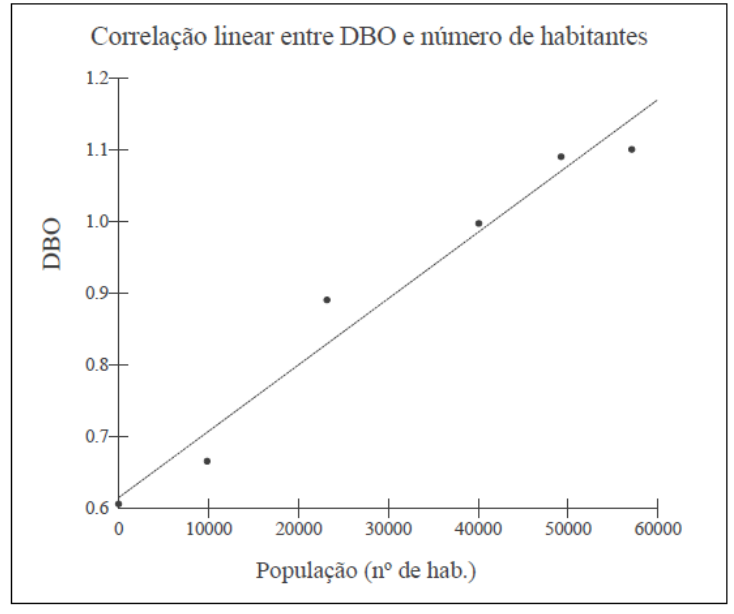

(b)

Figura 5 - (a) Correlação linear entre DQO e número de habitantes; (b) Correlação linear entre DBO e número de habitantes nos seis pontos de coleta no rio Uraim. Paragominas - PA.

Fonte: Autores (2017)

A análise dos dados indicou que: (1) a população da Área 1 tem influência sobre o $\mathrm{P}_{2}$; (2) a soma das populações das áreas 1 e 2 interfere nos valores de DBO e DQO no $\mathrm{P}_{3}$; (3) $\mathrm{P}_{4}$, por sua vez, é afetado pelo número total de habitantes das áreas 1,2 e 3 ; (4) $\mathrm{P}_{5}$ pelo número total das áreas 1, 2, 3 e 4; e (5) $\mathrm{P}_{6}$ é influenciado pela população total de todas as 5 áreas, uma vez que o rio transporta a matéria orgânica no sentido de $\mathrm{P}_{1}$ a $\mathrm{P}_{6}$ (Tabela 4). 


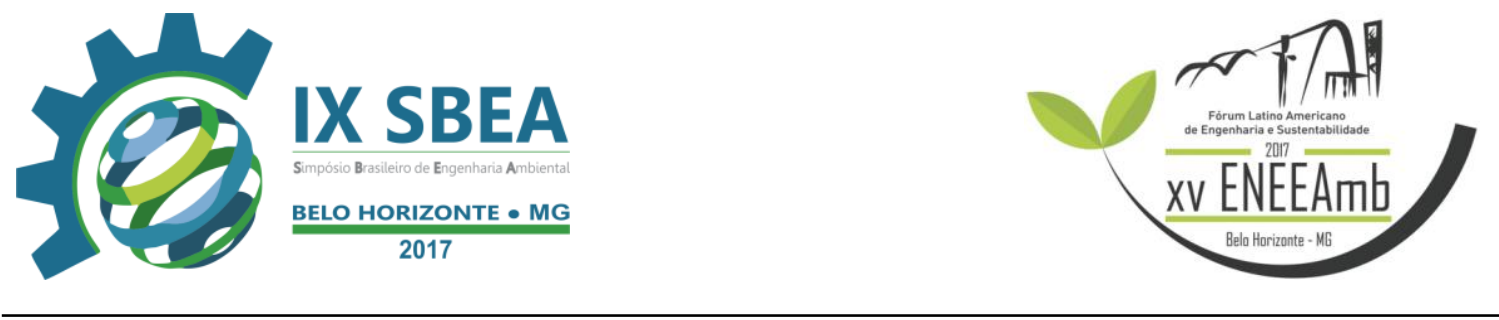

Tabela 4 - População estimada total que interfere nos valores de DBO e DQO de cada ponto devido à geração e disposição final de efluentes domésticos. Paragominas - PA.

\begin{tabular}{|c|c|c|c|c|c|c|}
\cline { 2 - 7 } \multicolumn{1}{c|}{} & $\mathrm{P}_{1}$ & $\mathrm{P}_{2}$ & $\mathrm{P}_{3}$ & $\mathrm{P}_{4}$ & $\mathrm{P}_{5}$ & $\mathrm{P}_{6}$ \\
\hline População (n ${ }^{\mathbf{o}}$ estimado de hab.) & 0 & 9842 & 23186 & 40064 & 49225 & 57081 \\
\hline $\mathrm{DBO}\left(\mathrm{mg} / \mathrm{L} \mathrm{O}_{2}\right)$ & 0.6056 & 0.6653 & 0.8906 & 0.9976 & 1.0906 & 1.1010 \\
\hline $\mathrm{DQO}\left(\mathrm{mg} / \mathrm{L} \mathrm{O}_{2}\right)$ & 1.06 & 1.17 & 1.57 & 1.76 & 1.92 & 1.94 \\
\hline
\end{tabular}

Vale ressaltar que $\mathrm{P}_{1}$ não sofre influência da urbanização, pois localiza-se antes da área urbana. Desse modo, os valores de DBO e DQO para esse ponto podem estar relacionados às atividades realizadas em propriedades rurais localizadas à montante. A interferência populacional na concentração dos parâmetros analisados ocorre, dentre outros, em função da recepção de efluentes domésticos que são despejados pela comunidade no corpo hídrico objeto dessa pesquisa. Apesar desse lançamento, os valores de DBO e DQO permanecem de acordo com o estabelecido pela Resolução n. 357:2005, do CONAMA, e por Chapman \& Kimstach (1996). Isso porque o rio continua como água superficial não poluída, o que pode estar relacionado à capacidade de autodepuração do corpo d'água.

\section{CONCLUSÕES E RECOMENDAÇÕES}

As Demandas Bioquímica e Química de Oxigênio sofrem influência do processo de urbanização, logo, o crescimento populacional urbano e rural são mecanismos que contribuem para a perda da qualidade da água. Dessa forma, recomenda-se que a fiscalização de atividades potenciais poluidoras do rio deva ser frequente e eficaz, com análises das concentrações de DBO e DQO. Além disso, as vias públicas devem ser mantidas limpas, para evitar a lixiviação de matéria orgânica e de outros resíduos em direção ao rio.

\section{REFERÊNCIAS BIBLIOGRÁFICAS}

ABNT. ASSOCIAÇÃO BRASILEIRA DE NORMAS TÉCNICAS. NBR 10739: determinação de oxigênio consumido: método do permanganato de potássio. Rio de Janeiro, 1989.

NBR 12614:

determinação da demanda bioquímica de oxigênio (DBO): método de incubação $\left(20^{\circ} \mathrm{C}\right.$, cinco dias). Rio de Janeiro, 1992. 


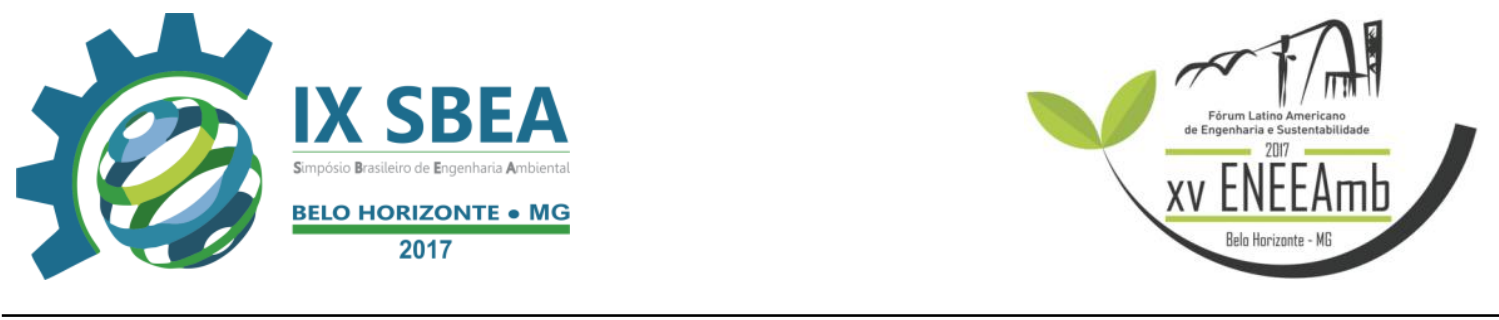

AYRES, M. et al. Programa BioEstat 5.3. Aplicações Estatísticas nas Áreas das Ciências Biológicas e Biomédicas. Belém: Sociedade Civil Mamirauá, 2005.

BASTOS, T. X. et al. Informações agroclimáticas do município de Paragominas para o planejamento agrícola. 2010. Disponível em: < https://ainfo.cnptia.embrapa.br/ digital/bitstream/item/102368/1/Nilza4.pdf >. Acesso em: 21 abr. 2017.

BITTENCOURT, H. R. Estatística Aplicada à Engenharia. Rio Grande do Sul: PUCRS, 2014. Disponível em: < http://www.feng.pucrs.br/professores/helio/Especializacao_ em_Engenharia_de_Processos_e_de_Sistemas_de_Producao/Estatistica/Material_Helio _FINAL_2014.pdf $>$. Acesso em: 30 abr. 2017.

BRANCO, S.M. Água: origem, uso e preservação. 2 ed. São Paulo: Moderna, 2010. $96 \mathrm{p}$.

BRASIL. Resolução $n^{0}$ 357, de 17 de março de 2005. Dispõe sobre a classificação dos corpos de água e diretrizes ambientais para o seu enquadramento, bem como estabelece as condições e padrões de lançamento de efluentes, e dá outras providências. Diário Oficial [da] República Federativa do Brasil, Poder Executivo, Brasília, DF, 18 mar, n. 53, p. 58-63.

CHAMPMAN, D.; KIMSTACH, V. Selection of water quality variables.. In: WHO; UNESCO; UNEP (Org). Water Quality Assessments: A Guide to Use of Biota, Sediments and Water in Environmental Monitoring. Chapman Edition, E\& FN Spon, London, 1996, 59-126.

IBGE. INSTITUTO BRASILEIRO DE GEOGRAFIA E ESTATÍSTICA. Censo 2010. 1 mapa interativo, color. Disponível em: < http://mapasinterativos.ibge.gov.br/grade/ default.html>. Acesso em: 30 de abr. 2017.

2016. Disponível em: <http://cidades.ibge.gov.br/xtras/perfil.php?

Cidades. codmun=150550>. Acesso em: 21 de abr. 2017.

LAZZEREIS, S. A. F. Avaliação e monitoramento da qualidade do rio Alegria. Medianeira, 35 p., 2013. Trabalho de Conclusão de Curso (Especialização em Gestão Ambiental em Municípios) - Universidade Tecnológica Federal do Paraná.

PINTO, A. et al. Diagnóstico Socioeconômico e Florestal do município de Paragominas. Relatório Técnico. Belém: Instituto do Homem e Meio Ambiente da Amazônia - Imazon. Disponível em: < http://imazon.org.br/PDFimazon/Portugues /outros/iagnostico-socioeconomico-e-florestal-do.pdf>. Acesso em: 21 abr. 2017. 65p. 


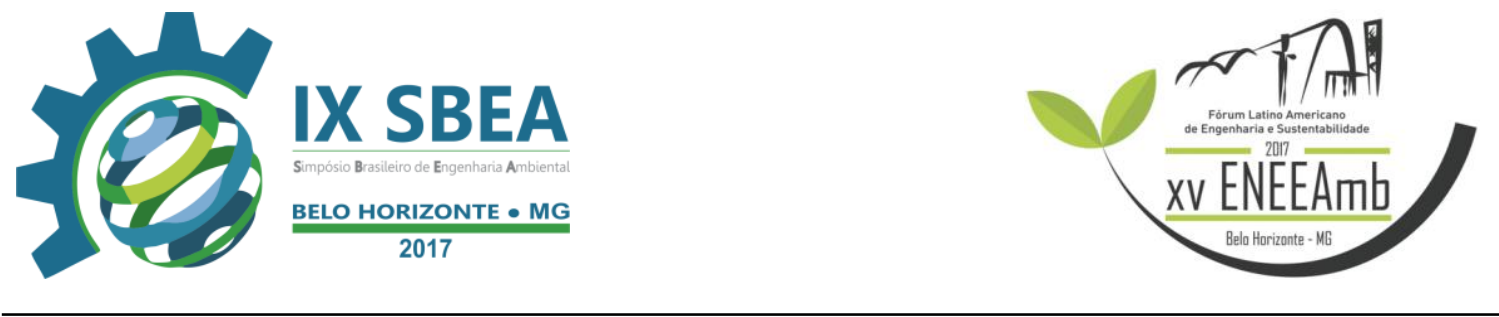

SANEPAR. AGÊNCIA DE SANEAMENTO DE PARAGOMINAS. Bacia do Uraim. 2014. Disponível em: < http://saneparagominas.com.br/agua/bacia_uraim/>. Acesso em: 21 abr. 2017.

SCALIZE, P. S. et al. Correlação entre os valores de DBO e DQO no afluente e efluente de duas ETEs da cidade de Araraquara. 2003. Disponível em: <http://www.saneamentobasico.com.br/portal/wp-ontent/uploads/2013/02/CORRELA\% C3\%87\%C3\%83O-ENTRE-OS-VALORES-DE-DBO-E-DQO-NO-AFLUENTE-EEFLUENTE.pdf>. Acesso em: 25 abr. 2017.

SHARMA, D.; KANSAL, A. Assessment of diffuse water pollution load from an urban catchment in India. Índia: Novatech, 2010. Disponível em: <http://documents. irevues.inist.fr/bitstream/handle/2042/35717/31710-384SHA.pdf? sequence=1 $>$. Acesso em: 22 abr. 2017. 